\title{
Vorrede zur deutschen Ausgabe.
}

Der Name Jules Janet ist jedem Arzte, der sich mit der Behandlung der Gonorrhöe abgibt, als derjenige des Erfinders der Janetschen Spülungen bekannt. Diese Spülungen bilden den Grundstock jeglicher Gonorrhöetherapie. In dem vorliegenden Lehrbuch hat Janet zum ersten Male die Erfahrungen seiner vierzigjährigen spezialärztlichen Tätigkeit in zusammenhängender Weise niedergelegt. Wir gewinnen in demselben Einblick in seine außergewöhnliche Erfahrung auf dem Gebiet der Gonorrhöetherapie. Wir sehen aber auch hinein in die Auffassung und in die Vorstellungen eines Meisters ärztlicher Kunst und ärztlichen Wissens vom Wesen der gonorrhoischen Erkrankungen, vom Werden, Gedeihen und Absterbender Gonokokken. Das vorliegende Buch, das in seiner französischen Urausgabe in sämtlichen Ärztekreisen höchstes Aufsehen erregt hat und schon nach einem halben Jahr vergriffen war, sodaß bereits eine zweite Auflage erscheinen mußte, zeigt uns, wie der Meister, der Jahrzehnte lang die Gonorrhöe studiert hat, das Leben der Gonokokken beobachtet hat und beinahe instinktiv fühlt, in welchem Stadium der Entwicklung sich die Keime befinden, ob es Zeit ist, sie heftig anzugreifen oder ob es besser ist, schonend gegen sie vorzugehen. Das Werk Janets hat ein ganz besonderes persönliches Gepräge. Auch derjenige, der in gewissen Fragen mit Janet nicht einig gehen kann, wird mit Freude und Interesse, zum eigenen Nutz und Frommen dieses Lehrbuch in die Hand nehmen und es immer wieder lesen. Es wird sicher vielen Forschern Anlaß und Anregung geben, die ganze Gonorrhöefrage von neuen Gesichtspunkten aus wieder aufzunehmen.

Straßburg i. E., den 12. Februar r931.

Asch. 